\title{
Call for Papers, CPSA 1984 Annual Meeting
}

Members of the Association are invited to submit proposals for papers to be presented at the Annual Meeting of the Canadian Political Science Association to be held at the University of Guelph, Guelph, Ontario, June 10, 11, and 12, 1984.

A proposal should include: a title; a summary (about 300 words) of the argument of the paper; a description of the method of analysis; and a complete address for authors and co-authors.

Proposals may be submitted to any member of the Programme Committee listed below. The Committee invites suggestions concerning topics for panels and plenary sessions as well as proposals for papers. Those which do not fit into any specific section should be sent to the chairperson.

The deadline for submission of proposals is November 4, 1983.

Completed papers should be not more than 30 pages in length, double-spaced, and should not have been previously published.

Papergivers are required to provide the CPSA secretariat with two copies of their paper by May 1 and to prepare up to 100 copies for distribution to members.

Programme Committee Chairperson: Michael Atkinson, Department of Political Science, McMaster University, Hamilton, Ontario L8S $4 M 4$

Vice-Chair: (1985 Chairperson) André Bernard, Département de science politique, Université du Québec à Montréal, Montréal, P.Q. H3C $3 E 9$

Local Representative: Pat Kyba, Depariment of Political Studies, University of Guelph, Guelph, Ontario NIG $2 W I$

Section

Canadian Politics

Provincial Politics

Public Policy, Administration and Law

Political Sociology/ Political Behaviour

Political Theory/ Political Analysis Papers under the rubric "Political Analysis and History" should be submitted to this section. If enough high-quality submissions are received, two separate series of sessions may be organized.

Comparative Politics: Western Capitalist

Comparative Politics: Third World and Socialist

Political Economy

International Relations

Local and Urban Politics

Plenaries/Special Sessions

\section{Section head}

André Bernard, Département de science politique, Université du Québec à Montréal, P.Q. H3C 3E9

Geoff Weller, Department of Political Science, Lakehead University, Thunder Bay, Ontario P7B 5E1

Carolyn Tuohy, Institute for Policy Analysis, University of Toronto, Toronto, Ontario M5S 1A1

Richard Price, Department of Political Science, University of Windsor, Windsor, Ontario N9B 3P4

Tom Lewis, Department of Political Science, McMaster University, Hamilton, Ontario L8S 4M4

Steven Bornstein, Department of Political Science, McGill

University, Montreal, P.Q. H3A 2T7

William Graf, Department of Political Studies, University of Guelph, Guelph, Ontario NIG 2W1

Rianne Mahon, School of Public Administration, Carleton University, Ottawa, Canada K1S 5B6

John Kirton, Department of Political Science, University of Toronto, Toronto, Ontario M5S 1A1

Andrew Sancton, Department of Political Science, University of Westem Ontario, London, Ontario N6A 5C2

Geoff Weller, Department of Political Science, Lakehead University, Thunder Bay, P7B SE1 